\title{
Exploration of Temperature-Dependent Thermal Conductivity and Diffusion Coefficient for Thermal and Mass Transportation in Sutterby Nanofluid Model over a Stretching Cylinder
}

\author{
Rabeeah Raza, ${ }^{1}$ Muhammad Sohail $\mathbb{D}^{1},{ }^{1}$ Thabet Abdeljawad $\mathbb{D}^{2,3,4}$ Rahila Naz, \\ and Phatiphat Thounthong ${ }^{5}$ \\ ${ }^{1}$ Department of Applied Mathematics and Statistics, Institute of Space Technology, P.O. Box 2750, Islamabad 44000, Pakistan \\ ${ }^{2}$ Department of Mathematics and General Sciences, Prince Sultan University, Riyadh, Saudi Arabia \\ ${ }^{3}$ Department of Medical Research, China Medical University, Taichung, Taiwan \\ ${ }^{4}$ Department of Computer Science and Information Engineering, Asia University, Taichung, Taiwan \\ ${ }^{5}$ Renewable Energy Research Centre, Department of Teacher Training in Electrical Engineering, Faculty of Technical Education, \\ King Mongkut's University of Technology North Bangkok, 1518 Pracharat 1 Road Bangsue, Bangkok 10800, Thailand
}

Correspondence should be addressed to Thabet Abdeljawad; tabdeljawad@psu.edu.sa

Received 28 June 2020; Revised 27 July 2020; Accepted 23 February 2021; Published 2 March 2021

Academic Editor: Marcio Eisencraft

Copyright (C) 2021 Rabeeah Raza et al. This is an open access article distributed under the Creative Commons Attribution License, which permits unrestricted use, distribution, and reproduction in any medium, provided the original work is properly cited.

\begin{abstract}
This declaration ponders the impacts of Joule warm, separation, and warming radiation for the progression of MHD Sutterby nanofluid past over an all-inclusive chamber. The wonder of warmth and mass conduction is demonstrated under warm conductivity relying upon temperature and dispersion coefficients individually. Besides, the conventional Fourier and Fick laws have been applied in the outflows of warm and mass transport. The control model comprising of a progression of coupled incomplete differential conditions is changed over into a standard arrangement of nonlinear coupled differential conditions by reasonable likeness changes. The subsequent arrangement of articulations is systematically treated through an ideal homotopic method. The impacts of various dimensionless stream boundaries on the speed, temperature, and focus fields are delineated through diagrams. The range of some parameters involved is assumed for the convergent solution as $0<R_{e}<10,0<P_{r}<6.5$, $0<E_{c}<40,0<R_{d}<1.5,0<S_{1}<0.5,0<S_{2}<0.5,0<L_{e}<0.5,0<N_{t}<2.5$, and $0<N_{b}<2.0$. The patterns of skin friction coefficient, local Nusselt, and Sherwood numbers are examined via bar charts. The principle consequence of the proposed study is that the decay of the speed for the Sutterby liquid boundary, the deterioration of the variable warm conductivity, the temperature, and the radiation increase the framework temperature. The delineation boundaries show the opposite conduct for the temperature and fixation outskirts layers.
\end{abstract}

\section{Introduction}

In the momentum period, non-Newtonian liquids are progressively significant for analysts as a result of their assorted applications in the mechanical field. For example, the assembling of polymers, gas turbines, power generators, glass fabrics, paper creation, wire drawing, and the sky is the limit from there. Sutterby liquid is one of the significant nonNewtonian fluids under the perceptions of the analysts. Among these, the Sutterby model addresses the high polymer fluid arrangements. It is one of the liquid models which expand the huge conduct of non-Newtonian liquids like pseudoplastic and dilatant liquids and it has the attributes to catch both the shear diminishing and shear thickening nature of the stream. Bilal et al. [1] researched Sutterby's MHD liquid stream in the Darcy medium. They performed OHAM to appraise the outcomes and found that speed demonstrated the contrary conduct for Darcy's opposition. Stale Sutterby liquid stream disregarding a contracting sheet highlighting the Cattaneo-Christov hypothesis going with heat retention/ age was dissected by Rehman et al. [2]. Nawaz [3] contemplated the warm execution of the mixture Sutterby nanofluid 
stream and applied the FEM strategy to process results. He noticed that surface warmth transition is higher on account of crossbreed nanofluid than that of the base liquid. Rana and Nawaz [4] delineated the warmth improvement model in Sutterby nanofluid stream. They likewise considered KooKleinstreuer and $\mathrm{Li}(\mathrm{KKL})$ Cattaneo-Christov heat motion models and found that temperature is altogether affected by the Joule warming impact. Sutterby nanofluid electromagnetohydrodynamic limit layer Darcy Forchheimer stream getting over an extending surface with a slip limit was clarified by Bilal et al. [5]. They applied the shooting technique modernized with Cash and Crap coefficients. They remarked that, in correlation with a traditional case, the drag on a superficial level for the Sutterby case shows a piddling pattern.

Warmth move is a significant wonder as it is an approach to move energy to obtain the necessary errand through various cycles. Warmth transport is needed in chilling of electrical thing, inner purifier with radiator, heat exchanger, chilling of reactor, and so forth. Transport of warmth and mass exchange assume a vital part in designing and modern fields. Trials show that steady warm conductivity and mass dispersion exist for extremely uncommon cases and results got with consistent properties do not approve for all circumstances. That is the reason there is a need to present a variable warm model. Variable thermophysical properties in the liquid stream are essential to expanding the productivity of the framework. Hayat et al. [6] examined blended, convected Casson liquid stream with temperature-subordinate warm conductivity. They contemplated heat move within the sight of gooey dispersal and find that warm limit upgrades for developing estimations of little boundary use to fluctuate warm conductivity. Temperature-subordinate warm conductivity in the stagnation guide stream of Jeffrey liquid to nonstraight extended surface having variable divider thickness is examined by Hayat et al. [7]. They expressed that temperature shows a decrease in the rising warm unwinding boundary. Khan et al. [8] endeavor to delineate the stagnation direct progression of the $2^{\text {nd }}$ grade to an impermeable extending chamber. They consider temperature-subordinate warm conductivity and warm definition and infer that Fourier's law model has a higher temperature than the Cattaneo-Christov heat motion model. Hammad et al. [9] examined radiation impact for the gooey liquid stream with temperature-subordinate thickness and warm conductivity disregarding a penetrable plate and pronounce that convective warmth move rots the temperature and speed of the stream.

Nanofluid is standing out enough to be noticed by scientists around the globe to expand the productivity of energy. Nanoparticles can assimilate straightforwardly from the wellspring of the episode radiation and improve the fluids radiative properties. Likewise, warm radiations alongside nanoparticles are primarily centered around the examination. They help in using sun-oriented energy as radiation heat moves. The sun is the less expensive source of the energy. Ijaz et al. [10] investigated the entropy and system of energy actuation and twofold compound response for the progression of nonlinear radiative Sisko liquid ignoring a radially stretchable rotatory circle. The huge ascribes of this examination are thick dispersal, Joule warming, and blended convection. Stagnation point blended convective MHD stream of cross nanofluid toward the surface which is extending straightly highlighting the idea of initiation energy shown by Khan et al. [11]. Parts of thermophoresis, Brownian movement, and nonlinear radiation are additionally introduced. They advise that for higher assessment of actuation energy variable types of focus rises. Stagnation point upper convective Maxwell nanofluid streaming over directly extending sheet alongside the credits of sun-oriented radiation and gooey dispersal was broken down by Khan et al. [12]. The shooting strategy is utilized to register results and they found that temperature is emphatically affected for radiative warmth move. Waqas et al. [13] noticed the effects of the attractive dipole and nonlinear warm radiation on liquid whose rheology was described via Carreau nanofluid. They applied the shooting technique to get an answer and expressed that the bigger ferrohydrodynamic connection variable tumbles down the speed.

Stratification has a critical part in the advancement of businesses. It applies in the dismissal framework, condensers, and nuclear power. Khan et al. [14] analyzed the impacts of variable consistency and warm separation on Williamson nanofluid over a nondirect extending sheet and reasoned that speed and temperature rot for bigger warm delineation boundaries. Axisymmetric Jeffrey liquid stagnation point stream over a slanted porous stretchable chamber was concentrated by Ijaz and Ayub [15]. The ramifications which are thought about are the CattaneoChristov hypothesis, warm separation, and homogeneousheterogeneous. They uncovered that temperature is diminishing the capacity of warm definition. Rehman et al. [16] outlined the blended convection digression exaggerated stream by extending round and hollow surface which is drenched in twofold defining media with no-slip conditions. They guaranteed that warm and solutal delineation is the reason for a decrease in temperature and convergence of the stream. Nanofluid extended stream with motile microorganisms with the ascribes of a slanted attractive field, definition, and gooey dissemination being inspected by Alsaedi et al. [17]. For additional investigations and examinations, perusers allude to the investigations announced in $[18,19]$.

Existing writing demonstrates that there is no examination so far to see the highlights of temperature-subordinate warm conductivity and mass dispersion coefficient for the progression of magnetohydrodynamic Sutterby nanofluid past over a stretchable chamber where warm radiation as sunlight based energy is assuming a significant part in the stream model with respect to the fact that its application is concerned. This correspondence fills this gap.

\section{Mathematical Modelling under Boundary Layer Theory (MMUBLT)}

The transportation of warmth and mass for the steady and incompressible two-dimensional Sutterby nanofluid stream on a stretch chamber involving variable thermophysical qualities is considered in the current examination in Figure 1. It additionally considers the ramifications of straight warm radiation, layering warm and focus, Joule warming, thermophoresis, Brownian movement, and slanted attractive power. The complete description of the modelled equations 


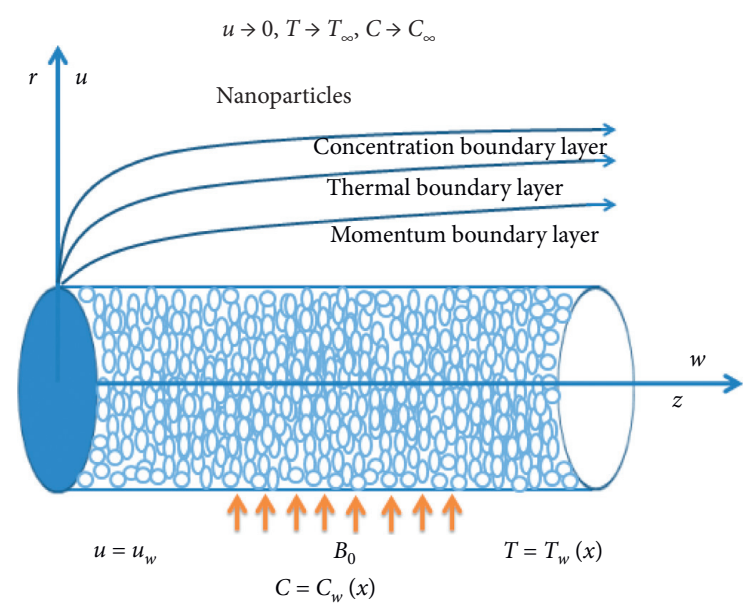

Figure 1: Geometry of the model under consideration.

is explained in Appendix. Sutterby's liquid model $[1,4,20,21]$ is characterized as

$$
\begin{aligned}
& S=\frac{\mu}{2}\left[\frac{\sinh ^{-1}(b \dot{\gamma})}{b \dot{\gamma}}\right]^{m} A_{1} . \\
& \frac{\partial u}{\partial r}+\frac{u}{r}+\frac{\partial w}{\partial z}=0, \\
& u \frac{\partial w}{\partial r}+w \frac{\partial w}{\partial z}=\frac{v_{f}}{2 r} \frac{\partial w}{\partial r}+\frac{v_{f}}{2} \frac{\partial^{2} w}{\partial r^{2}} \\
& -\frac{\nu_{f} m b^{2}}{4}\left(\frac{\partial w}{\partial r}\right)^{2} \frac{\partial^{2} w}{\partial r^{2}}-\frac{\delta_{f} B_{0}^{2}}{\rho_{f}} \sin ^{2} \alpha w, \\
& \left.\begin{array}{l}
\left(\rho c_{p}\right)_{f}\left(u \frac{\partial T}{\partial r}+w \frac{\partial T}{\partial z}\right)=\frac{1}{r} \frac{\partial}{\partial r}\left(r K(T) \frac{\partial T}{\partial r}\right)+\frac{16 \sigma^{*} T_{\infty}^{3}}{3 k^{*}} \frac{\partial^{2} T}{\partial r^{2}}+\delta_{f} B_{0}^{2} \sin ^{2} \alpha w^{2} \\
+\left(\rho c_{p}\right)_{p}\left[D_{B} \frac{\partial T}{\partial r} \frac{\partial C}{\partial r}+\frac{D_{t}}{T_{\infty}}\left(\frac{\partial T}{\partial r}\right)^{2}\right]
\end{array}\right\}, \\
& u \frac{\partial C}{\partial r}+w \frac{\partial C}{\partial z}=\frac{1}{r} \frac{\partial}{\partial r}\left(r D(T) \frac{\partial C}{\partial r}\right)+\frac{D_{t}}{T_{\infty}}\left(\frac{\partial^{2} T}{\partial r^{2}}+\frac{1}{r} \frac{\partial T}{\partial r}\right) .
\end{aligned}
$$

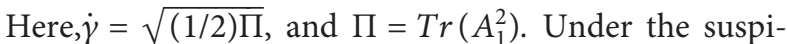
cion of limit layer, the demonstrated incomplete differential condition framework relating to the protection laws of mass, movement, warmth, and species transport is given as

The marvel considered with various actual perspectives considered is in Figure 1. Related limit conditions are

$$
\begin{aligned}
& u=0, \\
& w=U_{w}=\frac{U_{0} z}{l}, \\
& T=T_{w}=T_{0}+\frac{a_{1} z}{l}, \\
& \left.C=C_{w}=C_{0}+\frac{b_{1} z}{l} \text { at } r=R, \quad\right\} . \\
& w \longrightarrow 0 \\
& T \longrightarrow T_{\infty}=T_{0}+\frac{a_{2} z}{l}, \\
& C \longrightarrow C_{\infty}=C_{0}+\frac{b_{2} z}{l} \text { as } r \longrightarrow \infty
\end{aligned}
$$

The numerical models for warm conductivity and mass dissemination coefficient are referenced as $[22,23]$

$$
\begin{aligned}
& K(T)=k_{\infty}\left[1+\varepsilon\left(\frac{T-T_{\infty}}{T_{w}-T_{0}}\right)\right], \\
& D(T)=D_{\infty}\left[1+\varepsilon_{1}\left(\frac{T-T_{\infty}}{T_{w}-T_{0}}\right)\right] .
\end{aligned}
$$

The similarity transformations mentioned below $[1,20]$ are used to convert equations (3)-(6) into coupled ordinary differential equations: 


$$
\begin{aligned}
& \eta=\sqrt{\frac{U_{0}}{v_{f} l} \frac{\left(r^{2}-R^{2}\right)}{2 R},} \\
& u=-\sqrt{\frac{\nu_{f} U_{0}}{l}} \frac{R}{r} f(\eta), \\
& w=\frac{U_{0} z}{l} f^{\prime}(\eta), \\
& \theta(\eta)=\frac{T-T_{\infty}}{T_{w}-T_{0}}, \\
& \varphi(\eta)=\frac{C-C_{\infty}}{C_{w}-C_{0}}
\end{aligned}
$$$$
\text { Exploiting the above-declared renovations, equations }
$$$$
\text { (3)-(6) are as the following formation: }
$$

$$
\left.\begin{array}{c}
\left.\begin{array}{c}
(1+2 \gamma \eta) f^{\prime \prime \prime}+2(\gamma+1) f^{\prime \prime}-2\left(f^{\prime}\right)^{2}-2 \beta \gamma R_{e}(1+2 \gamma \eta)\left(f^{\prime \prime}\right)^{3} \\
-2 \beta R_{e}(1+2 \gamma \eta)^{2}\left(f^{\prime \prime}\right)^{2} f^{\prime \prime \prime}-M \sin ^{2} \alpha f^{\prime}=0
\end{array}\right\}, \\
(1+2 \gamma \eta) \theta^{\prime \prime}+P_{r \infty} f \theta^{\prime}+2 \gamma \theta^{\prime}+N_{b \infty}(1+2 \gamma \eta) \theta^{\prime} \varphi^{\prime} \\
+N_{t}(1+2 \gamma \eta)\left(\theta^{\prime}\right)^{2}+R_{d \infty}\left[(1+2 \gamma \eta) \theta^{\prime \prime}+\gamma \theta^{\prime}\right] \\
+P_{r \infty} E_{c} M \sin ^{2} \alpha\left(f^{\prime}\right)^{2}-P_{r \infty}\left(S_{1}+\theta\right) f^{\prime}=0,
\end{array}\right\},
$$

Transformed conditions for equations (9)-(11) are

$$
\begin{aligned}
f & =0, \\
f^{\prime} & =1, \\
\theta & =1-S_{1}, \\
\varphi & =1-S_{2} \text { at } \eta=0, \\
f^{\prime} & \longrightarrow 0, \\
\theta & \longrightarrow 0, \\
\varphi & \longrightarrow 0 \text { as } \eta \longrightarrow \infty,
\end{aligned}
$$

where

$$
\begin{aligned}
& P_{r \infty}=P_{r}(1+\varepsilon \theta), \\
& N_{b \infty}=\frac{N_{b}}{\left(1+\varepsilon_{1} \theta\right)}, \\
& R_{d \infty}=R_{d}(1+\varepsilon \theta) .
\end{aligned}
$$
have

Incorporating equation (13) in equations (10)-(11), we

$$
\left.\begin{array}{l}
(1+2 \gamma \eta) \theta^{\prime \prime}+P_{r}(1+\varepsilon \theta) f \theta^{\prime}+2 \gamma \theta^{\prime}+\frac{N_{b}}{\left(1+\varepsilon_{1} \theta\right)}(1+2 \gamma \eta) \theta^{\prime} \varphi^{\prime} \\
+N_{t}(1+2 \gamma \eta)\left(\theta^{\prime}\right)^{2}+R_{d}(1+\varepsilon \theta)\left[(1+2 \gamma \eta) \theta^{\prime \prime}+\gamma \theta^{\prime}\right] \\
+P_{r}(1+\varepsilon \theta) E_{c} M \sin ^{2} \alpha\left(f^{\prime}\right)^{2}-P_{r}(1+\varepsilon \theta)\left(S_{1}+\theta\right) f^{\prime}=0
\end{array}\right\},
$$$$
N_{b}(1+2 \gamma \eta) \varphi^{\prime \prime}+2 N_{b} \gamma \varphi^{\prime}+N_{b} L_{e}\left[f \varphi^{\prime}-\left(S_{2}+\varphi\right) f^{\prime}\right]+N_{t}\left(1+\varepsilon_{1} \theta\right)\left[(1+2 \gamma \eta) \theta^{\prime \prime}+2 \gamma \theta^{\prime}\right]=0 .
$$ 
The dimensionless parameters which are shown in the above equations are defined as follows:

$$
\begin{aligned}
& \gamma=\frac{1}{R} \sqrt{\frac{v_{f} l}{U_{0}}}, \\
& \beta=\frac{m b^{2} U_{0}^{2}}{4 l^{2}}, \\
& M=\frac{\delta_{f} B_{0}^{2} l}{\rho_{f} U_{0}}, \\
& R_{e}=\frac{U_{0} Z^{2}}{v_{f} l}, \\
& P_{r}=\frac{v_{f}\left(\rho c_{p}\right)_{f}}{k_{\infty}}, \\
& S_{1}=\frac{a_{1}}{a_{2}}, \\
& E_{c}=\frac{b_{1}}{c_{p}\left(T_{w}-T_{0}\right)}, \\
& R_{d}=\frac{\left(\rho c_{p}\right)_{p} D_{\infty}\left(T_{w}-T_{0}\right)}{v_{f}\left(\rho c_{p}\right)_{f} T_{\infty}}, \\
& N_{b}=\frac{\left(\rho c_{p}\right)_{p} D_{B}\left(C_{w}-C_{0}\right)}{v_{f}\left(\rho c_{p}\right)_{f}},
\end{aligned}
$$

\section{Graphical Analysis and Physical Interpretation and Justification}

4.1. Influence of Involved Parameters on Fluid Velocity. The emerging nonlinear arrangement of conditions has been handled by means of OHAM. The union of the applied calculation by processing the blunders is introduced in Table 1. In the current segment effect of various boundaries on stream, profiles have been examined as charts and their representation is incorporated. Figures $2-5$ are plotted to examine the conduct of speed concerning diverse dimensionless boundaries. In Figures 2 and 3 one can see the combined impact of Reynold number $\left(R_{e}\right)$, Sutterby fluid parameter $(\beta)$, and curvature parameter $(\gamma)$ on both dimensionless components of velocities $f(\eta)$ and $f^{\prime}(\eta)$, respectively. The fluid becomes denser for higher values of $\left(R_{e}\right)$ which as a result slows downs the fluid motion due to the fact that velocity shows a decline curve. Also, growing value of fluid parameter shows the same reversing behaviour on fluid motion because physically increasing $(\beta)$ means enhancement in relaxation time which dominates the viscous effect and produces resistance to fluid flow. So, the impact of curvature parameter is concerned with higher curvature showing the fast fluid flow in both velocity profiles. Figures 4 and 5 are presented to show the impact of magnetic parameter $(M)$ along with its angle of inclination
Coefficient of Skin erosion [1] and neighborhood warmth and mass transitions boundaries in nondimensional structures are deciphered as

$$
\begin{aligned}
c_{f}= & R_{e}^{1 / 2}\left[f^{\prime \prime}(0)-\frac{\beta}{4} f^{\prime \prime}(0)\left(4 f^{\prime}(0)+4 \gamma^{2} f^{2}(0)\right.\right. \\
& \left.\left.-4 f(0) f^{\prime}(0)+\lambda f^{\prime \prime 2}(0)\right)\right], \\
\mathrm{Nu}_{z}= & -R_{e}^{1 / 2}\left[1+\frac{4}{3} R_{d}+\varepsilon \theta\right] \theta^{\prime}(0), \\
\mathrm{Sh}_{z}= & -R_{e}^{1 / 2}(1+\varepsilon \theta) \varphi^{\prime}(0),
\end{aligned}
$$


TABLE 1: Convergence examination of established series solutions.

\begin{tabular}{lccc}
\hline $\mathbf{m}$ & $\widehat{\mathbf{E}}_{k}^{f}$ & $\widehat{\mathbf{E}}_{k}^{\theta}$ & $\widehat{\mathbf{E}}_{k}^{\varphi}$ \\
\hline 2 & 0.0112614 & 0.0046921 & 0.00524505 \\
4 & 0.00310299 & 0.000317258 & 0.00178006 \\
6 & 0.0011439 & 0.0000852381 & 0.00102513 \\
8 & 0.000360455 & 0.0000447833 & 0.000739084 \\
10 & 0.0000862807 & 0.0000279075 & 0.00059564 \\
12 & 0.0000206196 & 0.0000195569 & 0.000510457 \\
14 & $6.83992 \times 10^{-6}$ & 0.0000148887 & 0.000453768 \\
16 & $2.71667 \times 10^{-7}$ & 0.0000116863 & 0.000412904 \\
18 & $9.56869 \times 10^{-7}$ & $9.26413 \times 10^{-6}$ & 0.000381734 \\
20 & $2.94672 \times 10^{-7}$ & $7.39892 \times 10^{-6}$ & 0.00035696 \\
\hline
\end{tabular}

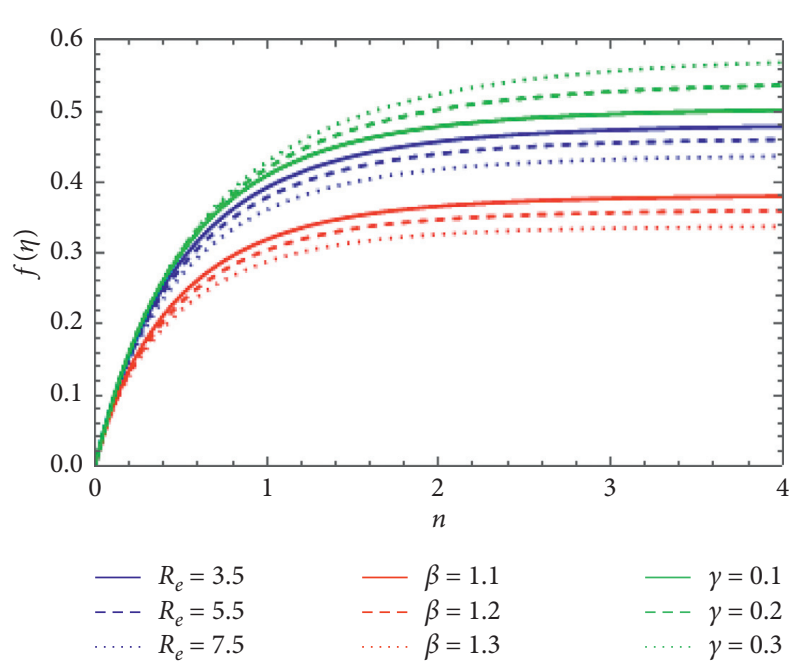

Figure 2: Influence of $R_{e}, \beta$, and $\gamma$ on $f(\eta)$

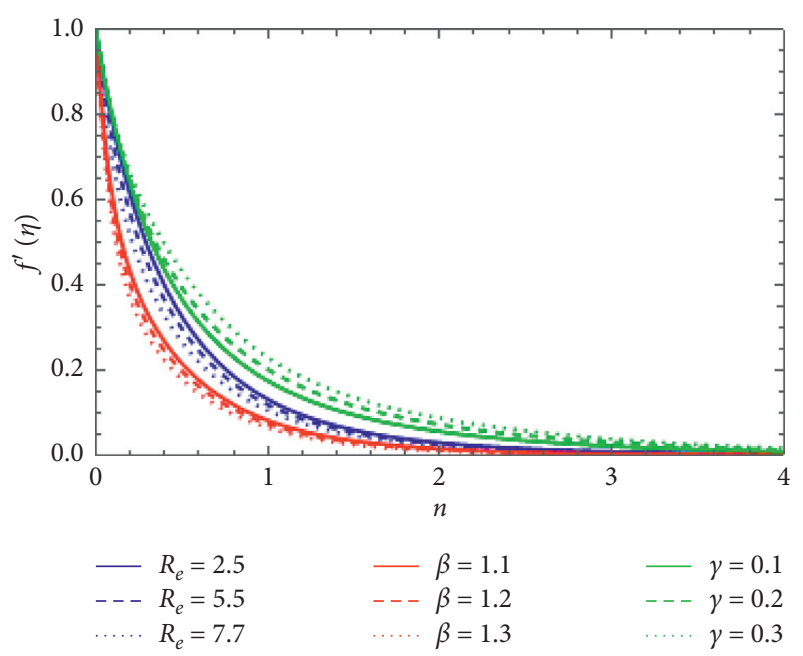

Figure 3: Influence of $R_{e}, \beta$, and $\gamma$ on $f^{\prime}(\eta)$.

( $\alpha$ ) on both velocity profiles $f(\eta)$ and $f^{\prime}(\eta)$, respectively. The growth in magnetic parameter results in arising the opposing Lorentz force to the fluid which downshifts the fluid motion. The same is the case with $(\alpha)$ as increasing the angle enhances the hold of the magnetic force on the flow. On the whole, velocity of the flow shows downturns when

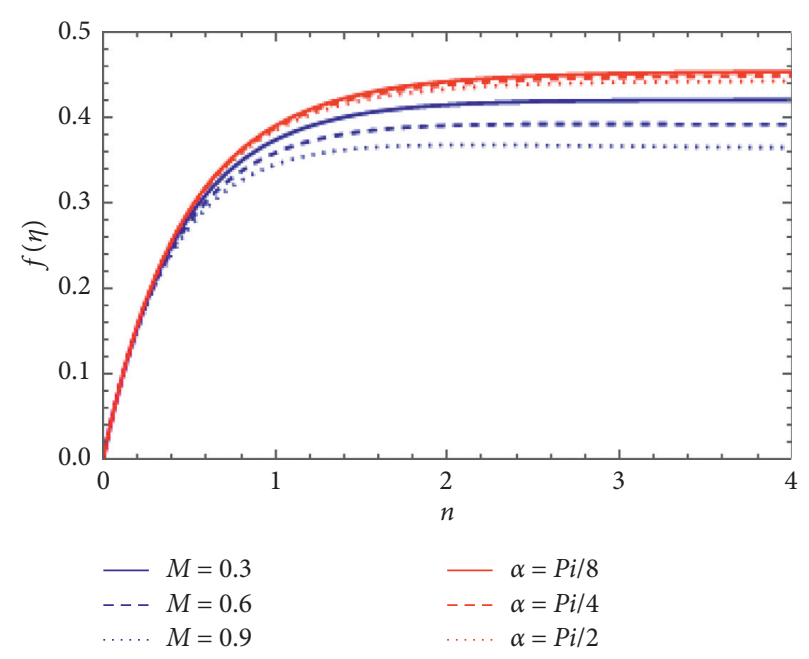

Figure 4: Influence of $M$ and $\alpha$ on $f(\eta)$.

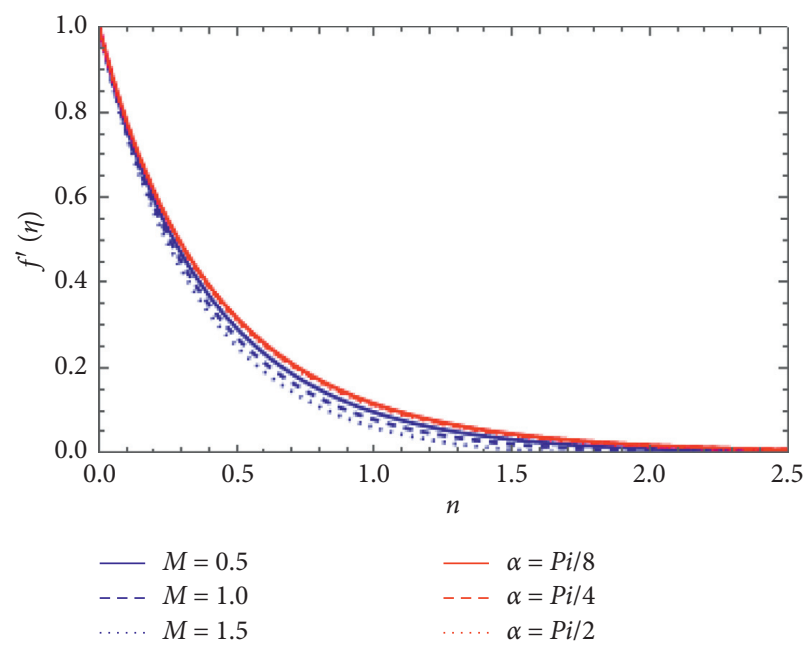

Figure 5: Influence of $M$ and $\alpha$ on $f^{\prime}(\eta)$.

any parameter becomes strong and creates resistance to the flow.

4.2. Comportment of Contributing Parameters on Temperature Field. Figures 6-14 are designed for the impact of several flow parameters on dimensionless temperature $\theta(\eta)$. Figure 6 shows the view of curvature impact on temperature $\theta(\eta)$. As velocity is an upsurging function of curvature and temperature is also defined through average kinetic energy. Higher curvature implies higher velocity which implies higher kinetic energy results in the rising temperature profile. The declining outturns of a small parameter $(\varepsilon)$ on temperature are shown in Figure 7 . For $(\varepsilon)=0$, the case reduces to normal temperature-independent thermal conductivity case and shows the maximum temperature on it which implies that variable thermal conductivity cools down the flow with higher temperature. Figure 8 shows the impact of the small parameter $\left(\varepsilon_{1}\right)$ (used to vary the diffusion coefficient) on temperature $\theta(\eta)$. For higher values of $\left(\varepsilon_{1}\right)$, the graph shows a rise in temperature. Figure 9 is portraying 


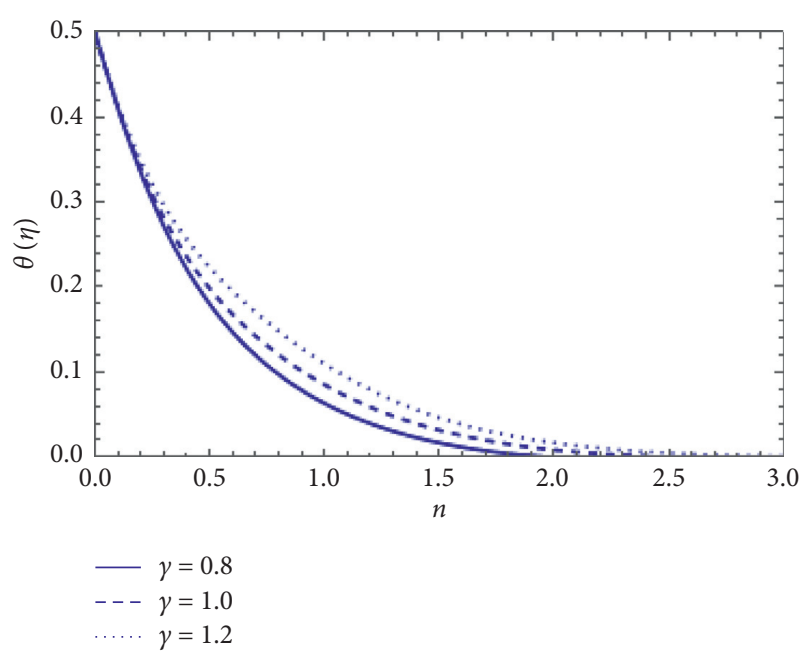

Figure 6: Influence of $\gamma$ on $\theta(\eta)$.

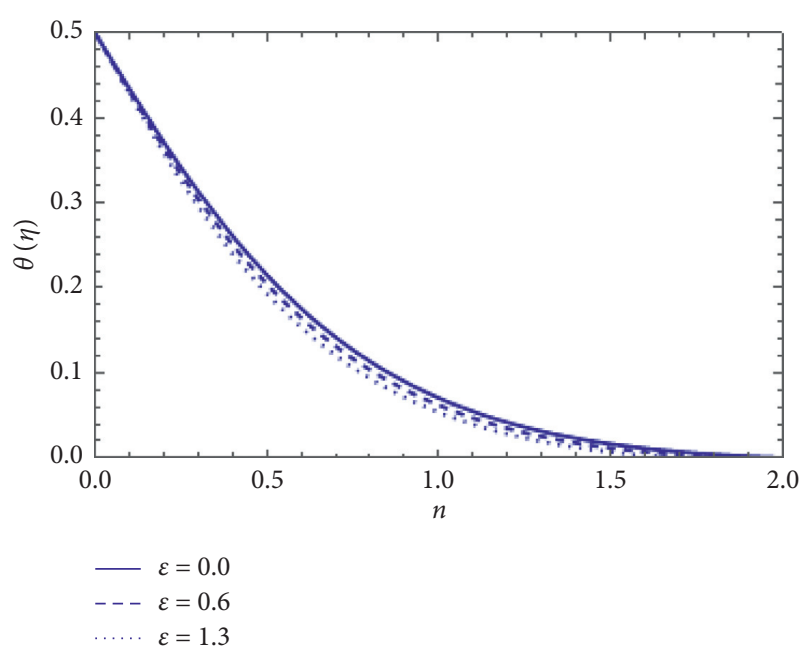

Figure 7: Influence of $\varepsilon$ on $\theta(\eta)$.

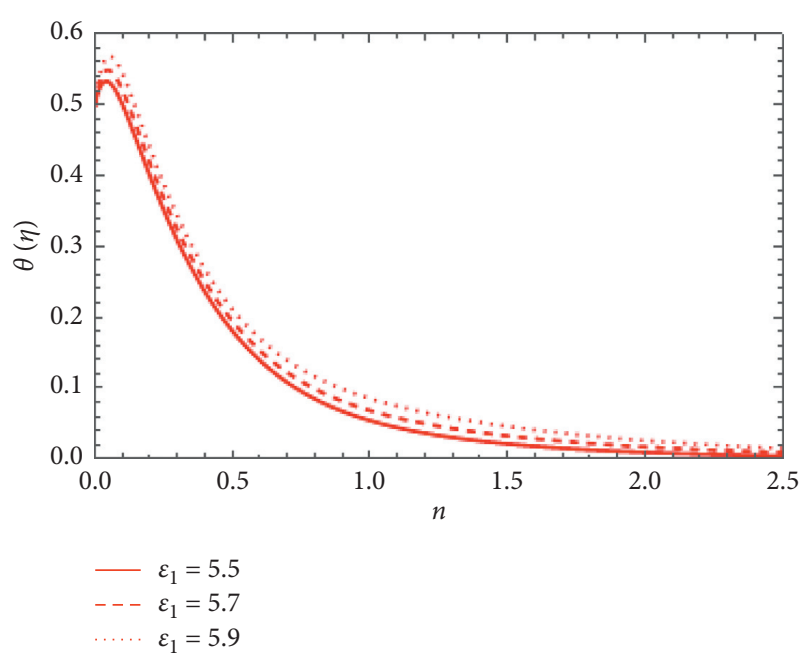

FIGURE 8: Influence of $\varepsilon_{1}$ on $\theta(\eta)$.

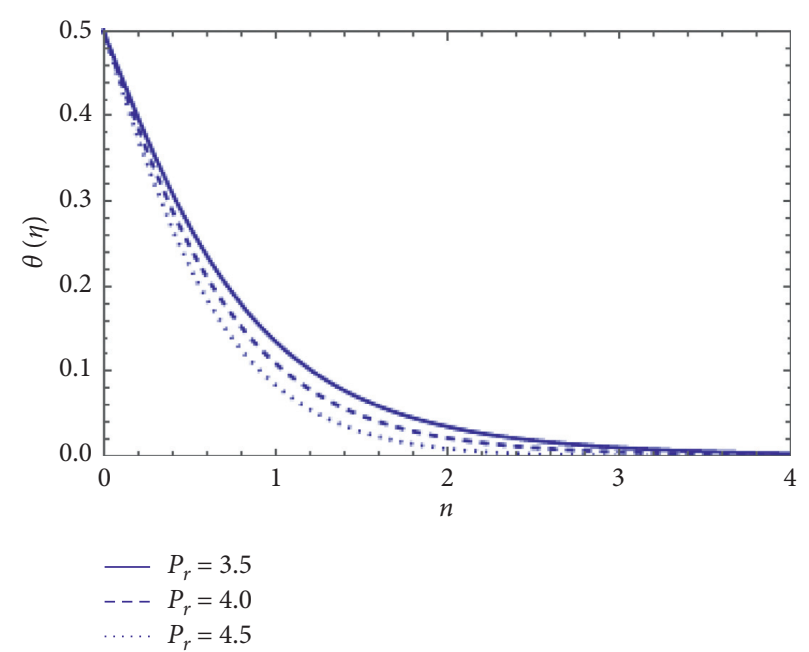

Figure 9: Influence of $P_{r}$ on $\theta(\eta)$.

the declining behaviour of temperature curves for growing values of Prandtl number $\left(P_{r}\right)$ since the thickness of the thermal boundary layer reduced by enhancing $\left(P_{r}\right)$. As Prandtl number is inversely related to thermal diffusivity, enhancing it results in cooling the flow. The combined impact of the Brownian motion parameter $\left(N_{b}\right)$ and thermophoresis parameter $\left(N_{t}\right)$ is depicted in Figure 10. Speeding the Brownian motion leads to the faster random motion of nanoparticles in a flow which shows an extension in thermal boundary layer thickness and enhances the temperature of flow more rapidly. A similar pattern is observed for growing values $\left(N_{t}\right)$. As in process of thermophoresis, more heated particles near the surface travel away from heated regions toward the cold region and raise temperature there and collective temperature of the whole system rises. Figure 11 illustrates the impression of radiation parameter $\left(R_{d}\right)$ on temperature $\theta(\eta)$. Radiation parameter tells about the relative contribution of heat transfer through conduction to thermal radiation. So, a clear upsurge in temperature curves is observed for escalating values of $\left(R_{d}\right)$. Enhancing thermal radiation means adding energy through radiation in the flow which eventually boosts the temperature distribution of the fluid. Figure 12 shows the impression of the Eckert number $\left(E_{c}\right)$ on dimensionless temperature $\theta(\eta)$. The growth in $\left(E_{c}\right)$ has a positive influence on heating the system due to the fact that it strengthens the kinetic energy of the flow. The graphical view for the behaviour of temperature when magnetic parameter $(M)$ and its inclination angle $(\alpha)$ are taken into account is illustrated in Figure 13. The resistive force which arises due to the presence of a magnetic field is the cause of boosting the temperature distribution of flow. Figure 14 is a pictorial illustration of the stratification parameter $\left(S_{1}\right)$ due to temperature difference. The thermal stratification process causes layer formation due to temperature variation, the enlarging stratification parameter falls down the temperature gradient between the wall and reference point, and thus the temperature of the system drops. 


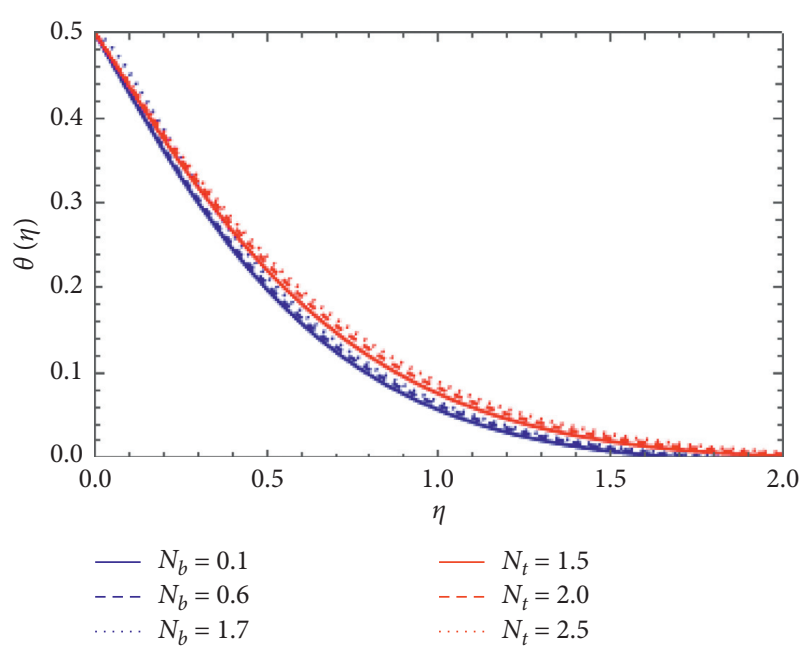

Figure 10: Influence of $N_{b}$ and $N_{t}$ on $\theta(\eta)$.

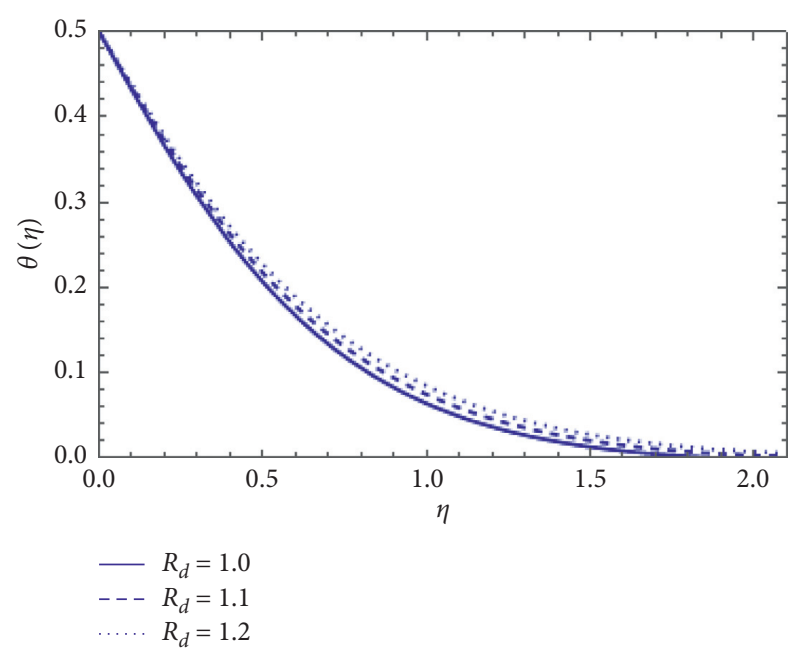

Figure 11: Influence of $R_{d}$ on $\theta(\eta)$.

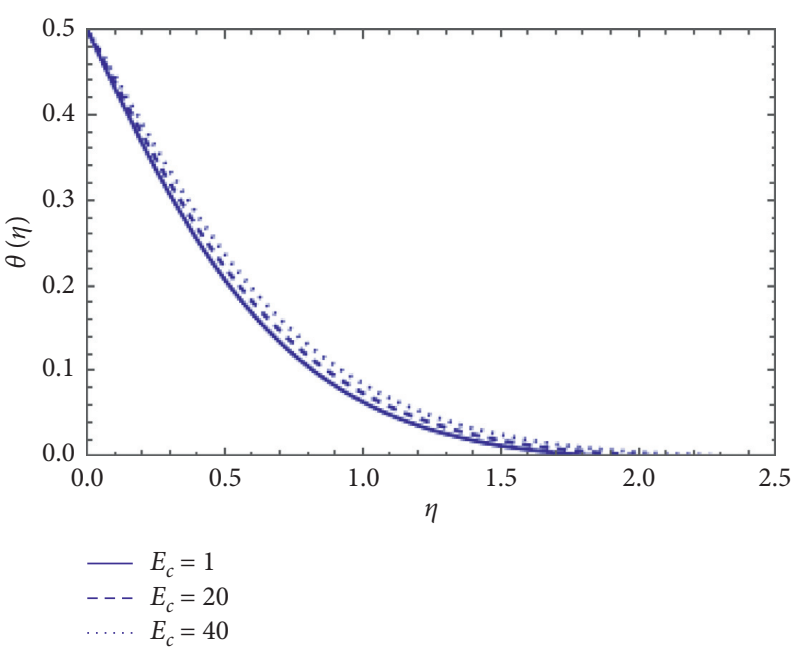

FigURE 12: Influence of $E_{c}$ on $\theta(\eta)$.

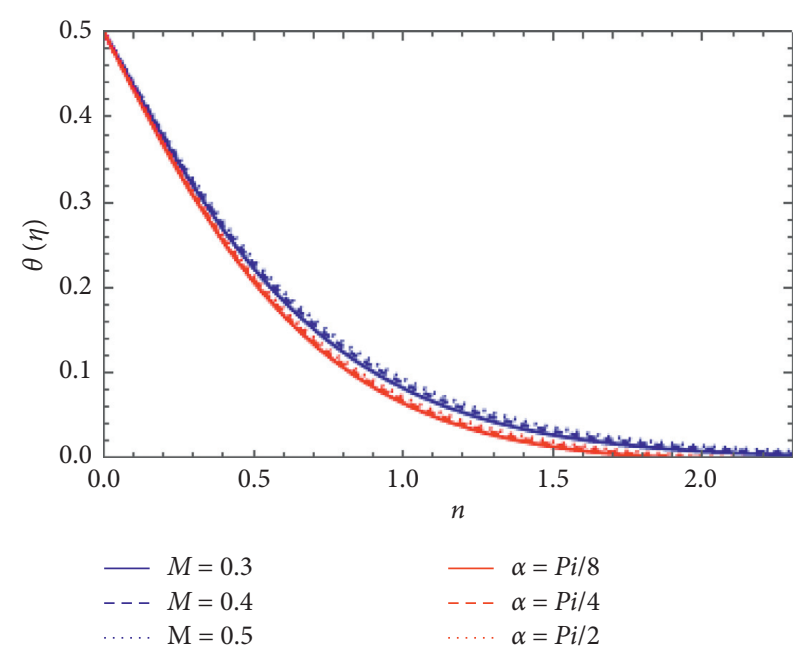

FIgURe 13: Influence of $M$ and $\alpha$ on $\theta(\eta)$.

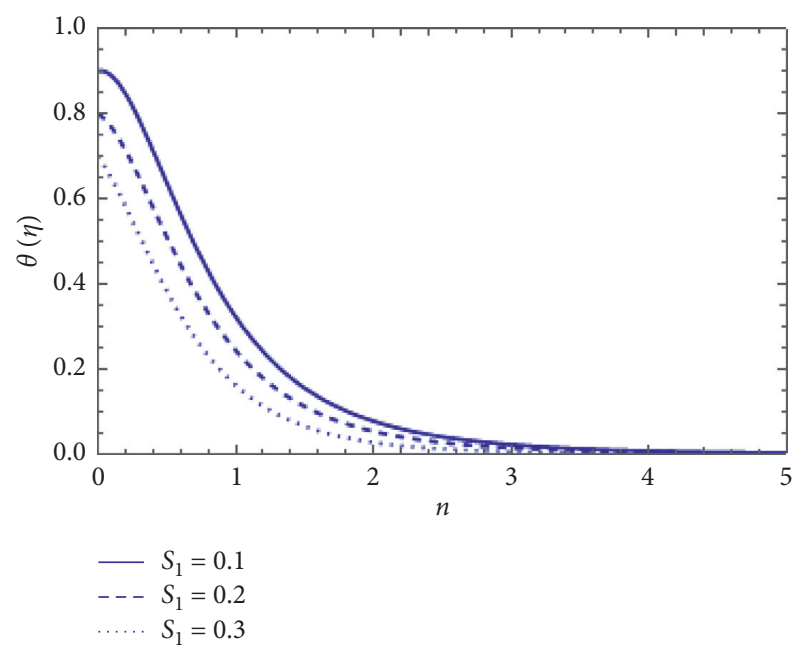

Figure 14: Influence of $\mathbf{S}_{1}$ on $\theta(\eta)$.

4.3. Bearing of Involved Parameters on Fluid Concentration Field. Figures 15-18 are mapped to describe the etiquette of dimensionless concentration $\phi(\eta)$ by the variety of different flow parameters. Figure 15 is an image of thermophoresis parameter $\left(N_{t}\right)$ influence on concentration. Boosting thermophoresis process boosts the traveling of particles from higher to lower temperature difference which as a result maximizes the concentration of nanoparticles in the flow regime. Figure 16 is plotted to understand the impact of Lewis's number $\left(L_{e}\right)$ on concentration $\phi(\eta)$. As $\left(L_{e}\right)$ gives the relation between the thermal boundary layer and the concentration boundary layer, physically, escalation in $\left(L_{e}\right)$ shrinks the thickness of the boundary layer of concentration. Figure 17 is planned to study the behaviour of concentration $\phi(\eta)$ on the basis of a small meter $\left(\varepsilon_{1}\right)$ (used to vary diffusion coefficient). An increasing behaviour is observed for elevating values of $\left(\varepsilon_{1}\right)$, Figure 18 is sketched to illustrate the impact of the stratification parameter $\left(S_{2}\right)$ due to concentration difference. The higher values of $\left(S_{2}\right)$ are a reason for the decline in concentration difference between wall and 


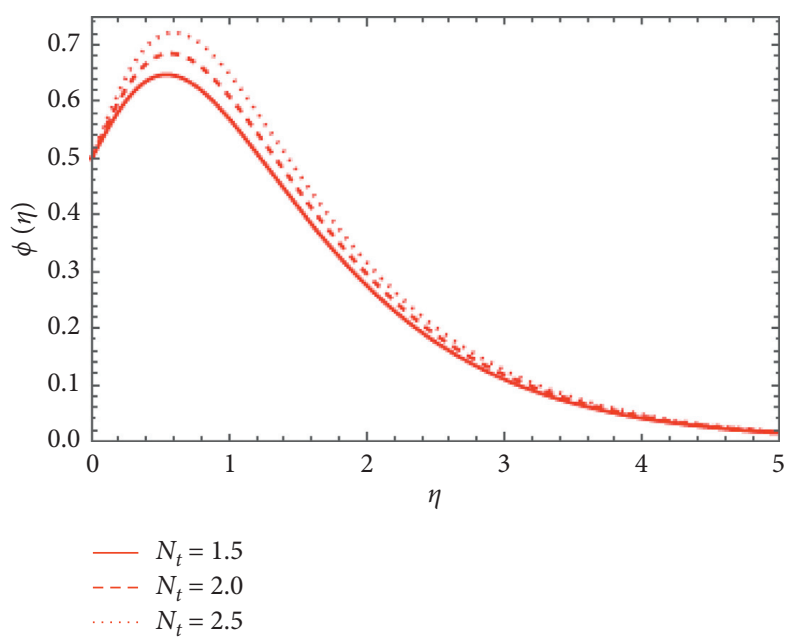

Figure 15: Influence of $\mathbf{N}_{\mathbf{t}} \mathbf{o n} \varphi(\eta)$.

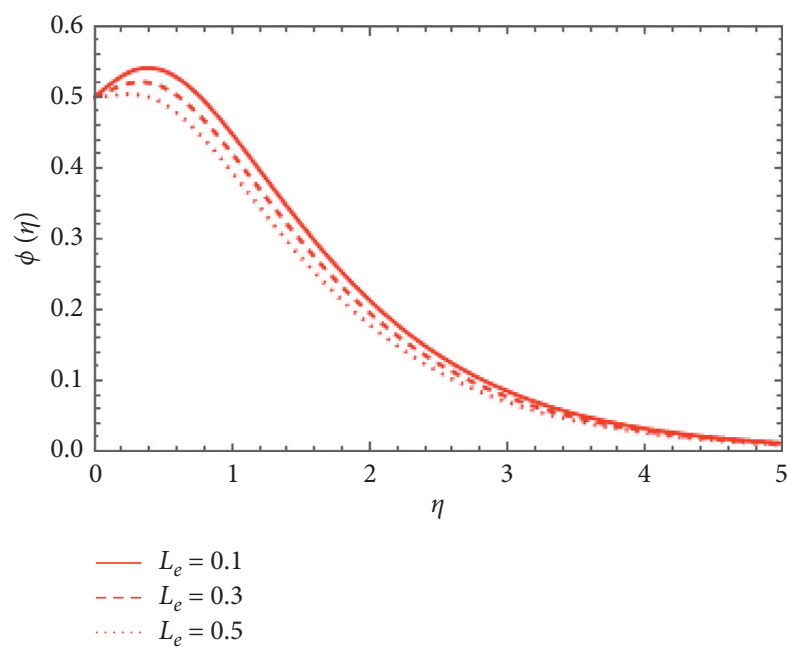

Figure 16: Influence ofl $\mathbf{L}_{\mathbf{e}}$ on $\varphi(\eta)$.

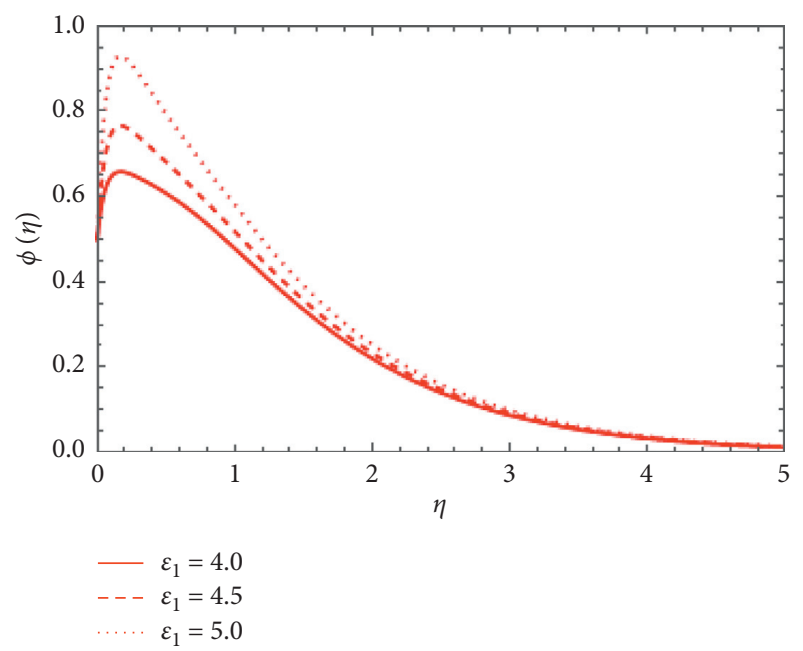

Figure 17: Influence of $\varepsilon_{1}$ on $\varphi(\eta)$.

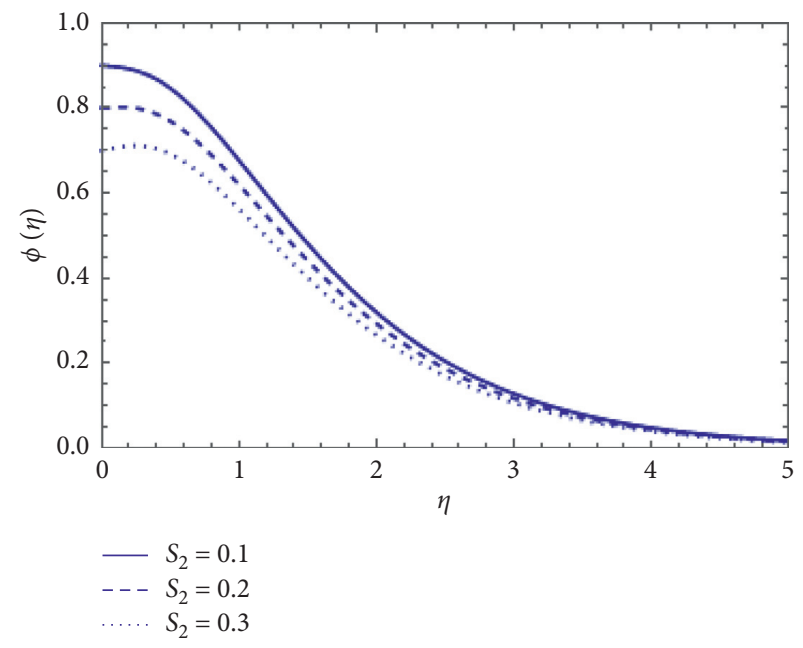

FIGURE 18: Influence of $\boldsymbol{S}_{2}$ on $\varphi(\eta)$.

reference point which as a result lessens the concentration boundary layer thickness.

4.4. Impacts of Involved Parameters on $\left(\mathbf{c}_{\mathbf{f}} \mathbf{R}_{\mathbf{e}}^{-1 / 2}\right),\left(\mathbf{N u}_{\mathbf{z}}\right.$ $\left.\mathbf{R}_{\mathrm{e}}^{-1 / 2}\right)$, and $\left(\mathbf{S h}_{\mathrm{z}} \mathbf{R}_{\mathrm{e}}^{-1 / 2}\right)$. Figures 19-21 are bar chart representation of coefficient of skin friction, local Nusselt number, and local Sherwood number based on several parameters. Figure 19 shows the illustration of the effect of the Sutterby fluid parameter $(\beta)$ on skin friction coefficient $\left(c_{f} R_{e}^{-1 / 2}\right)$. Enhancing $(\beta)$ has a reverse reaction on flow velocity as it enhances the viscous nature of the fluid due to which opposing force arises which is the cause of boosting the skin friction coefficient. Figure 20 gives a pictorial view for the impressions of radiation parameter $\left(R_{d}\right)$ on the heat flux in the form of local Nusselt number $\left(\mathrm{Nu}_{z} R_{e}^{-1 / 2}\right)$. Higher radiation parameter lowers the local Nusselt number as it also has a reverse effect on the momentum boundary layer. Physical temperature gradient at the wall surface becomes small which lowers natural convection ability. Figure 21 


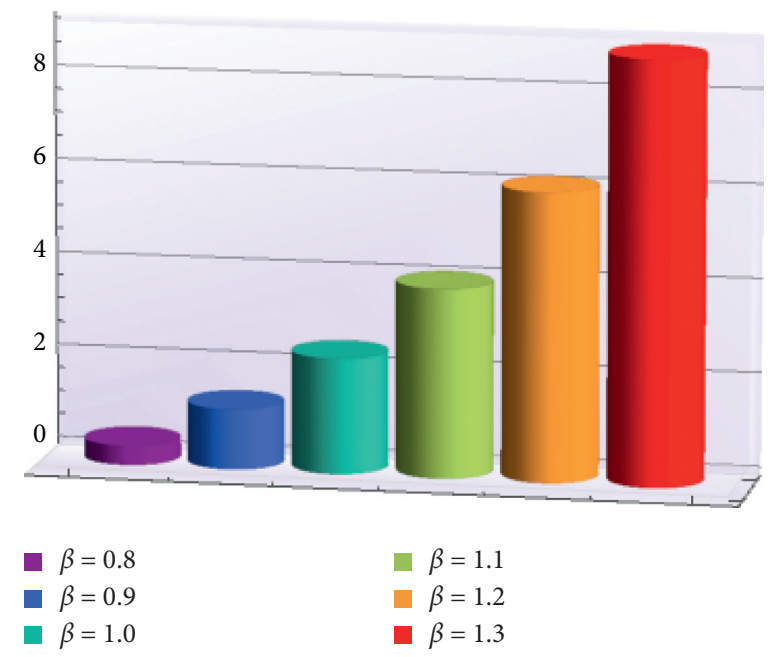

Figure 19: Influence of $\beta$ on skin friction coefficient $\mathbf{c}_{\mathbf{f}} \mathbf{R}_{\mathbf{e}}^{-1 / 2}$.

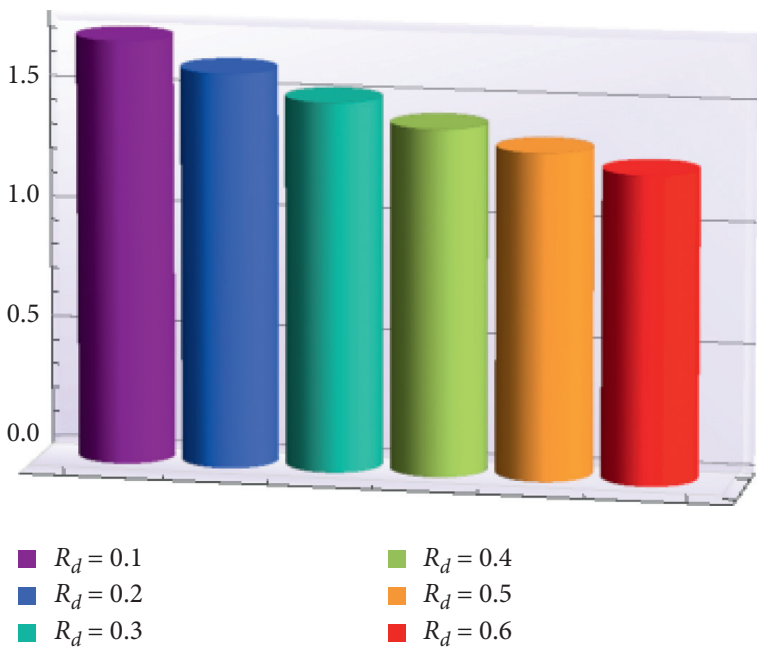

Figure 20: Influence of $\mathbf{R}_{\mathbf{d}}$ on local Nusselt number $\mathbf{N}_{\mathbf{u z}} \mathbf{R}_{\mathbf{e}}^{-1 / 2}$.

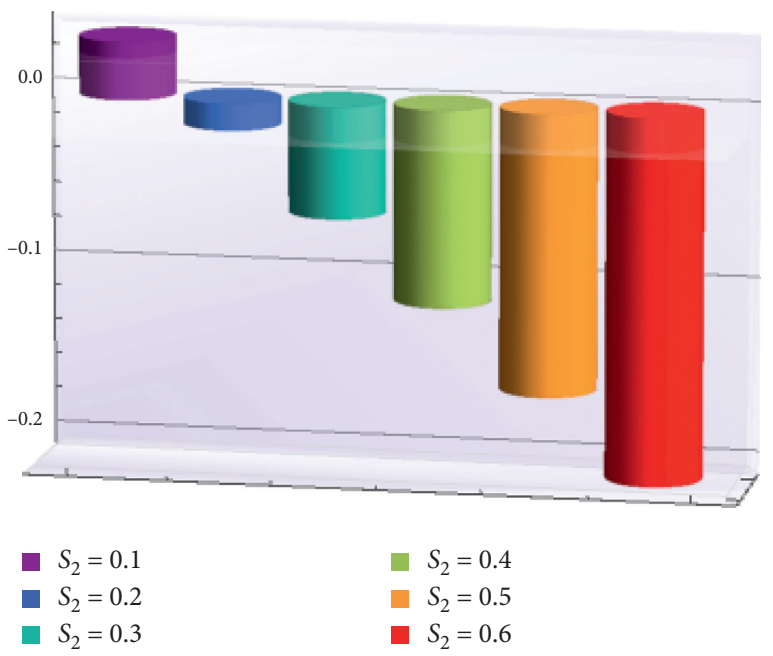

Figure 21: Influence of $\mathbf{S}_{2}$ on local Sherwood number $\mathbf{S}_{\mathrm{hz}} \mathbf{R}_{\mathrm{e}}^{-1 / 2}$.
TABle 2: Comparative study for skin friction coefficient.

\begin{tabular}{lcc}
\hline$\gamma$ & $f^{\prime \prime}(0)[28]$ & $f^{\prime \prime}(0)$ present \\
\hline 0 & -1.000 & -2.415979950137716 \\
0.25 & -1.094378 & -2.472779362585112 \\
0.5 & -1.188715 & -2.540875718491212 \\
0.75 & -1.281833 & -2.5979549320909516 \\
1 & -1.459308 & -2.599693623769820 \\
\hline
\end{tabular}

shows the footprints of stratification concentration parameter $\left(S_{2}\right)$ on local Sherwood number $\left(\mathrm{Sh}_{z} R_{e}^{-1 / 2}\right)$ and the bar chart shows a reverse behaviour for the escalation in $\left(S_{2}\right)$. In Table 2, a limiting case of dimensionless stress is computed and a comparison is established. It is found that, due to the factor 2 in the momentum equation, our results are differing by the multiple of 2 . If we ignore 2 , our results exactly match with the precious finding.

\section{Conclusion and Key Points of Current Research}

In the course of the study, a two-dimensional stationary radiation flux of Sutterby nanofluid with an oblique magnetic field and with variable thermophysical properties was taken under observation. To solve the system of transformed ODEs, the OHAM scheme was applied. The main findings of this study are as follows:

Larger curvature $(\gamma)$ boosts both velocity and temperature profiles.

Small parameter $(\varepsilon)$ reduces the temperature and $\left(\varepsilon_{1}\right)$ shows opposite behaviour.

Radiation parameter $\left(R_{d}\right)$ has a positive impact on the temperature profile.

Velocity field slows down for higher Reynolds number $\left(R_{e}\right)$, magnetic parameter $(M)$, and Sutterby fluid parameter $(\beta)$. 
Larger values of stratification parameters $\left(S_{1}\right)$ and $\left(S_{2}\right)$ reduce the thermal and concentration boundary layer thickness in flow.

Skin friction increases with an increase in Sutterby fluid parameter and radiation decays the local Nusselt number.

Augmentation in Eckert number and radiation parameter enhance the thermal transport.

\section{Nomenclature}

$u, w:$

$T:$

$T_{\infty}:$

$T_{0}$ :

$T_{w}$ :

C:

$\mathrm{C}_{\infty}:$

$\mathrm{C}_{0}$ :

$C_{w}$ :

$\sigma^{*}:$

$U_{w}$ :

$\delta_{f}$ :

$\alpha:$

$\rho_{f}$ :

$K(T)$ :

$\left(c_{p}\right)_{p}:$

$\varepsilon$ :

$\eta:$

$\theta(\eta)$ :

$M$ :

$a_{1}, a_{2}, b_{1}, b_{2}$

$D_{b}$ :

$v_{f}$ :

$m:$

$b$ :

$B_{0}$ : $D(T)$ :

$k^{*}$ :

$N_{b}$ :

$N_{t}$ :

$R_{e}$ :

$P_{r}$ :

$R_{d}$ :

$E_{c}$ :

$L_{e}$ :

$S_{1}$ :

$S_{2}$ :
Velocity component in $r$ and $z$ directions $\mathrm{ms}^{-1}$ Temperature Kelvin

Ambient temperature Kelvin

Reference temperature Kelvin

Wall temperature Kelvin

Concentration of nanoparticles 1

Ambient concentration 1

Reference concentration 1

Wall concentration 1

Stefan-Boltzmann constant $\mathrm{eVk}^{-1}$

Wall velocity $\mathrm{ms}^{-1}$

Electrical conductivity $\mathrm{s}^{3} \mathrm{~m}^{2} \mathrm{~kg}^{-1}$

Angle of inclination 1

Density of fluid $\mathrm{kgm}^{-3}$

Heat capacity of fluid $\mathrm{m}^{2} \mathrm{~s}^{-2} \mathrm{k}^{-1}$

Small parameter 1

Dimensionless parameter 1

Dimensionless temperature 1

Hartmann number 1

: Dimensionless constant $\mathrm{s}^{-1}$

Brownian diffusion coefficient 1

Fluid viscosity $\mathrm{m}^{2} \mathrm{~s}^{-1}$

Power law index 1

Sutterby fluid parameter $\mathrm{s}$

Magnetic field strength Tesla

Variable thermophoresis diffusion coefficient $\mathrm{m}^{2} \mathrm{~s}^{-1}$

Mean absorption coefficient 1

Brownian motion parameter 1

Thermophoresis parameter 1

Reynold number 1

Prandtl number 1

Radiation number 1

Eckert number 1

Lewis number 1

Thermal stratification parameter 1

Mass stratification parameter 1
Thermal conductivity $\mathrm{Wm}^{-1} \mathrm{k}^{-1}$ $\left(c_{p}\right)_{f}: \quad$ Heat capacity of particles $\mathrm{m}^{2} \mathrm{~s}^{-2} \mathrm{k}^{-1}$

$\varepsilon_{1}$ :

$f(\eta)$

$\phi(\eta)$

$\beta$ :

$\gamma:$

Small parameter 1

Dimensionless velocity 1

Dimensionless concentration 1

Sutterby fluid variable 1

Curvature parameter 1 .

\section{Appendix}

\section{A. Derivation of the Momentum Equation}

A.1. Derivation of Momentum Equation, Referred to as Equation (3) in the Article. Sutterby fluid model [1-5, 20, 21] is defined as

$$
S=\frac{\mu}{2}\left[\frac{\sinh ^{-1}(b \dot{\gamma})}{b \dot{\gamma}}\right]^{m} A_{1}
$$

Here, $\dot{\gamma}=\sqrt{(1 / 2) \Pi}$ and $\Pi=\operatorname{Tr}\left(A_{1}^{2}\right)$

The approximated form of (A.1) is given as

$$
S \cong \frac{\mu}{2}\left[1-m \frac{(b \dot{\gamma})^{2}}{6}+\cdots\right] .
$$

As we are working in $r$ and $z$ coordinates, we have

$\nabla V=\left[\begin{array}{ccc}\frac{\partial u}{\partial r} & 0 & \frac{\partial u}{\partial z} \\ 0 & \frac{u}{r} & 0 \\ \frac{\partial w}{\partial r} & 0 & \frac{\partial w}{\partial z}\end{array}\right]$

$$
A_{1}=\left[\begin{array}{ccc}
2 \frac{\partial u}{\partial r} & 0 & \frac{\partial u}{\partial z}+\frac{\partial w}{\partial r} \\
0 & 2 \frac{u}{r} & 0 \\
\frac{\partial w}{\partial r}+\frac{\partial u}{\partial z} & 0 & 2 \frac{\partial w}{\partial z}
\end{array}\right],
$$

$$
\dot{\gamma}^{2}=2\left(\frac{\partial u}{\partial r}\right)^{2}+\left(\frac{\partial u}{\partial z}+\frac{\partial w}{\partial r}\right)^{2}+2\left(\frac{u}{r}\right)^{2}+2\left(\frac{\partial w}{\partial z}\right)^{2}
$$

The components stress tensor on the basis of the above expressions is given as 


$$
\begin{aligned}
& S_{r r}=\frac{\mu}{2}\left[1-\frac{m b^{2}}{6}\left\{2\left(\frac{\partial u}{\partial r}\right)^{2}+\left(\frac{\partial u}{\partial z}+\frac{\partial w}{\partial r}\right)^{2}+2\left(\frac{u}{r}\right)^{2}+2\left(\frac{\partial w}{\partial z}\right)^{2}\right\}\right] 2 \frac{\partial u}{\partial r}, \\
& S_{r \theta}=S_{\theta r}=S_{\theta z}=S_{z \theta}=0, \\
& S_{r z}=\frac{\mu}{2}\left[1-\frac{m b^{2}}{6}\left\{2\left(\frac{\partial u}{\partial r}\right)^{2}+\left(\frac{\partial u}{\partial z}+\frac{\partial w}{\partial r}\right)^{2}+2\left(\frac{u}{r}\right)^{2}+2\left(\frac{\partial w}{\partial z}\right)^{2}\right\}\right]\left(\frac{\partial u}{\partial z}+\frac{\partial w}{\partial r}\right), \\
& S_{\theta \theta}=\frac{\mu}{2}\left[1-\frac{m b^{2}}{6}\left\{2\left(\frac{\partial u}{\partial r}\right)^{2}+\left(\frac{\partial u}{\partial z}+\frac{\partial w}{\partial r}\right)^{2}+2\left(\frac{u}{r}\right)^{2}+2\left(\frac{\partial w}{\partial z}\right)^{2}\right\}\right] 2 \frac{u}{r}, \\
& S_{z z}=\frac{\mu}{2}\left[1-\frac{m b^{2}}{6}\left\{2\left(\frac{\partial u}{\partial r}\right)^{2}+\left(\frac{\partial u}{\partial z}+\frac{\partial w}{\partial r}\right)^{2}+2\left(\frac{u}{r}\right)^{2}+2\left(\frac{\partial w}{\partial z}\right)^{2}\right\}\right] 2 \frac{\partial w}{\partial z} .
\end{aligned}
$$

For the particular flow situation, momentum equation is given as follows:

(r-momentum):

$$
\rho_{f}\left(u \frac{\partial u}{\partial r}+w \frac{\partial u}{\partial z}\right)=\frac{1}{r} \frac{\partial}{\partial r}\left(r S_{r r}\right)+\frac{\partial}{\partial z} S_{r z} .
$$

After incorporating all the terms and applying boundary layer approximations, no term will remain in $\mathrm{r}$-momentum.

(z-momentum):

$$
\rho_{f}\left(u \frac{\partial w}{\partial r}+w \frac{\partial w}{\partial z}\right)=\frac{1}{r} \frac{\partial}{\partial r}\left(r S_{r z}\right)+\frac{\partial}{\partial z} S_{z z}-\delta_{f} B_{0}^{2}(\sin \alpha)^{2} w .
$$

After incorporating all the terms and applying boundary layer approximations, we have

$$
\begin{aligned}
\rho_{f}\left(u \frac{\partial w}{\partial r}+w \frac{\partial w}{\partial z}\right)= & -\frac{\mu m b^{2}}{12}\left[\frac{\partial}{\partial r}\left(\frac{\partial u}{\partial z}\left(\frac{\partial w}{\partial r}\right)^{2}\right)+\frac{1}{r} \frac{\partial u}{\partial z}\left(\frac{\partial w}{\partial r}\right)^{2}\right. \\
& \left.+2 \frac{\partial}{\partial z}\left(\frac{\partial w}{\partial z}\left(\frac{\partial w}{\partial r}\right)^{2}\right)\right]-\delta_{f} B_{0}^{2}(\sin \alpha)^{2} w \\
u \frac{\partial w}{\partial r}+w \frac{\partial w}{\partial z}= & \frac{v_{f}}{2 r} \frac{\partial w}{\partial r}+\frac{\nu_{f}}{2} \frac{\partial^{2} w}{\partial r^{2}}-\frac{v_{f} m b^{2}}{4}\left(\frac{\partial w}{\partial r}\right)^{2} \frac{\partial^{2} w}{\partial r^{2}} \\
& -\frac{\delta_{f} B_{0}^{2}(\sin \alpha)^{2} w}{\rho_{f}} .
\end{aligned}
$$

A.2. Derivation of the Energy Equation, Referred to as Equation (4) in the Article. Effects considered in the energy equation are as follows:

Linear radiation [21]

Brownian motion [20].
Thermophoresis [20].

Joule heating.

On the basis of considering the effects of energy equation is written as

$$
\begin{aligned}
\left(\rho c_{p}\right) \frac{\mathrm{d} T}{f}= & \nabla^{2}(K(T) T)-\nabla \cdot q_{r}+\frac{1}{\delta_{f}} J \cdot J \\
& +\left(\rho c_{p}\right)_{p}\left(\nabla(D(T) T) \cdot \nabla C+\frac{D_{t}}{T_{\infty}} \nabla T \cdot \nabla T\right),
\end{aligned}
$$

where

$$
\begin{gathered}
\frac{\mathrm{d} T}{\mathrm{~d} t}=u \frac{\partial T}{\partial r}+w \frac{\partial T}{\partial z} \\
\nabla^{2}(K(T) T)=\frac{1}{r} \frac{\partial}{\partial r}\left(r K(T) \frac{\partial T}{\partial r}\right)+K(T) \frac{\partial^{2} T}{\partial z^{2}} .
\end{gathered}
$$

So,

$$
q_{r}=-\left(\frac{4 \sigma^{*}}{3 k^{*}}\right) \frac{\partial T^{4}}{\partial r}
$$

Temperature variation is assumed in such a way that Taylor series approximation of $T^{4}$ about $T_{\infty}$ is obtained

$$
\begin{aligned}
& T^{4}=\left(T-T_{\infty}\right)^{4}, \\
& T^{4} \cong 4 T T_{\infty}^{3}-3 T_{\infty}^{4}, \\
& q_{r}=-\left(\frac{16 \sigma^{*} T_{\infty}^{3}}{3 k^{*}}\right) \frac{\partial T}{\partial r}, \\
&-\nabla \cdot q_{r}=\left(\frac{16 \sigma^{*} T_{\infty}^{3}}{3 k^{*}}\right) \frac{\partial^{2} T}{\partial r^{2}} .
\end{aligned}
$$


Also,

$$
\begin{aligned}
\frac{1}{\delta_{f}} J \cdot J & =\frac{1}{\delta_{f}}\left(0,0, \delta_{f} B_{0} \sin \alpha w\right) \cdot\left(0,0, \delta_{f} B_{0} \sin \alpha w\right), \\
\frac{1}{\delta_{f}} J \cdot J & =\delta_{f} B_{0}^{2}(\sin \alpha)^{2} w^{2}, \\
\left(\nabla(D(T) T) \cdot \nabla C+\frac{D_{t}}{T_{\infty}} \nabla T \cdot \nabla T\right) & =\left(\frac{\partial}{\partial r}(T D(T)) \frac{\partial C}{\partial r}+D(T) \frac{\partial T}{\partial z} \frac{\partial C}{\partial Z}\right)+D_{t}\left[\left(\frac{\partial T}{\partial r}\right)^{2}+\left(\frac{\partial T}{\partial z}\right)^{2}\right] .
\end{aligned}
$$

Substituting all above expressions in (A.8) and after applying boundary layer approximation, we arrived at the final form as

$$
\begin{aligned}
\left(\rho c_{p}\right)_{f}\left(u \frac{\partial T}{\partial r}+w \frac{\partial T}{\partial z}\right)= & \frac{1}{r} \frac{\partial}{\partial r}\left(r K(T) \frac{\partial T}{\partial r}\right)+\frac{16 \sigma^{*} T_{\infty}^{3}}{3 k^{*}} \frac{\partial^{2} T}{\partial r^{2}}+\delta_{f} B_{0}^{2} \sin ^{2} \alpha w^{2} \\
& +\left(\rho c_{p}\right)_{p}\left[\frac{\partial}{\partial r}(T D(T)) \frac{\partial C}{\partial r}+\frac{D_{t}}{T_{\infty}}\left(\frac{\partial T}{\partial r}\right)^{2}\right] .
\end{aligned}
$$

\section{Data Availability}

The data will be available upon reasonable request to the corresponding author.

\section{Conflicts of Interest}

The authors declare that there are no conflicts of interest.

\section{Authors' Contributions}

All the authors read and approved the manuscript.

\section{Acknowledgments}

Thabet Abdeljawad would like to thank Prince Sultan University for funding this work through research group Nonlinear Analysis Methods in Applied Mathematics (NAMAM) group no. RG-DES-2017-01-17.

\section{References}

[1] S. Bilal, M. Sohail, R. Naz, and M. Y. Malik, "Dynamical and optimal procedure to analyse the exhibition of physical attribute imparted by Sutterby magneto nano fluid in Darcy medium yield by axially stretched cylinder," Canadian Journal of Physics, vol. 98, no. 1, 2019.

[2] S. U. Rehman, N. A. Mir, M. S. Alqarni, M. Farooq, and M. Y. Malik, "Analysis of heat generation/absorption in thermally stratified Sutterby fluid flow with CattaneoChristov theory," Microsystem Technologies, vol. 25, no. 9, pp. 3365-3373, 2019.
[3] M. Nawaz, "Role of hybrid nanoparticles in thermal performance of Sutterby fluid, the ethylene glycol," Physica A: Statistical Mechanics and Its Applications, vol. 537, Article ID 122447, 2020.

[4] S. Rana and M. Nawaz, "Investigation of enhancement of heat transfer in Sutterby nanofluid using Koo-Kleinstreuer and Li (KKL) correlations and Cattaneo-Christov heat flux model," Physica Scripta, vol. 94, no. 11, 2019.

[5] S. Bilal, M. Sohail, R. Naz, M. Y. Malik, and M. Alghamdi, "Upshot of Ohmically dissipated Darcy-Forchheimer slip flow of magnetohydrodynamic Sutterby fluid over radiating linearly stretched surface in view of cash and carp method," Applied Mathematics and Mechanics, vol. 40, pp. 861-876, 2019.

[6] T. Hayat, M. I. Khan, M. Waqas, T. Yasmeen, and A. Alsaedi, "Viscous dissipation effect in flow of magnetonanofluid with variable properties," Journal of Molecular Liquids, vol. 222, pp. 47-54, 2016.

[7] T. Hayat, M. I. Khan, M. Farooq, A. Alsaedi, M. Waqas, and T. Yasmeen, "Impact of Cattaneo-Christov heat flux model in flow of variable thermal conductivity fluid over a variable thicked surface," International Journal of Heat and Mass Transfer, vol. 99, pp. 702-710, 2016.

[8] M. I. Khan, Q. M. Z. Zia, A. Alsaedi, and T. Hayat, "Thermally stratified flow of second grade fluid with non-Fourier heat flux and temperature dependent thermal conductivity," Results in Physics, vol. 8, pp. 799-804, 2018.

[9] M. A. A. Hamad, M. J. Uddin, and A. I. M. Ismail, "Radiation effects on heat and mass transfer in MHD stagnation-point flow over a permeable flat plate with thermal convective surface boundary condition, temperature dependent viscosity and thermal conductivity," Nuclear Engineering and Design, vol. 242, pp. 194-200, 2012. 
[10] M. Ijaz, M. Ayub, and H. Khan, "Entropy generation and activation energy mechanism in nonlinear radiative flow of Sisko nanofluid: rotating disk," Heliyon, vol. 5, no. 6, Article ID e01863, 2019.

[11] M. I. Khan, T. Hayat, M. I. Khan, and A. Alsaedi, "Activation energy impact in nonlinear radiative stagnation point flow of Cross nanofluid," International Communications in Heat and Mass Transfer, vol. 91, pp. 216-224, 2018.

[12] M. Khan, T. Salahuddin, A. Tanveer, M. Y. Malik, and A. Hussain, "Change in internal energy of thermal diffusion stagnation point Maxwell nanofluid flow along with solar radiation and thermal conductivity," Chinese Journal of Chemical Engineering, vol. 27, no. 10, pp. 2352-2358, 2019.

[13] M. Waqas, S. Jabeen, T. Hayat, M. I. Khan, and A. Alsaedi, "Modeling and analysis for magnetic dipole impact in nonlinear thermally radiating Carreau nanofluid flow subject to heat generation," Journal of Magnetism and Magnetic Materials, vol. 485, pp. 197-204, 2019.

[14] M. Khan, T. Salahuddin, M. Y. Malik, and F. O. Mallawi, "Change in viscosity of Williamson nanofluid flow due to thermal and solutal stratification," International Journal of Heat and Mass Transfer, vol. 126, pp. 941-948, 2018.

[15] M. Ijaz and M. Ayub, "Thermally stratified flow of Jeffrey fluid with homogeneous-heterogeneous reactions and non-Fourier heat flux model," Heliyon, vol. 5, no. 8, Article ID e02303, 2019.

[16] K. U. Rehman, A. A. Khan, M. Y. Malik, I. Zehra, and U. Ali, "Temperature and concentration stratification effects on nonNewtonian fluid flow past a cylindrical surface," Results in Physics, vol. 7, pp. 3659-3667, 2017.

[17] A. Alsaedi, M. I. Khan, M. Farooq, N. Gull, and T. Hayat, "Magnetohydrodynamic (MHD) stratified bioconvective flow of nanofluid due to gyrotactic microorganisms," Advanced Powder Technology, vol. 28, no. 1, pp. 288-298, 2017.

[18] M. I. Khan, M. Waqas, T. Hayat, M. I. Khan, and A. Alsaedi, "Behavior of stratification phenomenon in flow of Maxwell nanomaterial with motile gyrotactic microorganisms in the presence of magnetic field," International Journal of $\mathrm{Me}$ chanical Sciences, vol. 131, pp. 426-434, 2017.

[19] R. Naz, M. Noor, Z. Shah, M. Sohail, P. Kumam, and P. Thounthong, "Entropy generation optimization in MHD pseudoplastic fluid comprising motile microorganisms with stratification effect," Alexandria Engineering Journal, vol. 59, no. 1, pp. 485-496, 2020.

[20] M. Sohail and R. Naz, "Modified heat and mass transmission models in the magnetohydrodynamic flow of Sutterby nanofluid in stretching cylinder," Physica A: Statistical Mechanics and its Applications, vol. 2020, Article ID 124088, 2020.

[21] M. Sohail, U. Nazir, Y. M. Chu, H. Alrabaiah, W. Al-Kouz, and $\mathrm{P}$. Thounthong, "Computational exploration for radiative flow of Sutterby nanofluid with variable temperature-dependent thermal conductivity and diffusion coefficient," De Gruyter, vol. 18, no. 1, 2020.

[22] S. I. Abdelsalam and M. Sohail, "Numerical approach of variable thermophysical features of dissipated viscous nanofluid comprising gyrotactic micro-organisms," Pramana: Journal of Physics, vol. 94, no. 1, 2020.

[23] M. Sohail, R. Naz, Z. Shah, P. Kumam, and P. Thounthong, "Exploration of temperature dependent thermophysical characteristics of yield exhibiting non-Newtonian fluid flow under gyrotactic microorganisms," AIP Advances, vol. 9, no. 12, Article ID 125016, 2019.
[24] M. Sohail, R. Naz, and S. I. Abdelsalam, "On the onset of entropy generation for a nanofluid with thermal radiation and gyrotactic microorganisms through 3D flows," Physica Scripta, vol. 95, no. 4, Article ID 045206, 2020.

[25] M. Sohail, R. Naz, and S. I. Abdelsalam, "Application of nonFourier double diffusions theories to the boundary-layer flow of a yield stress exhibiting fluid model," Physica A: Statistical Mechanics and Its Applications, vol. 537, Article ID 122753, 2020.

[26] M. Sohail and R. Raza, “Analysis of radiative magneto nano pseudo-plastic material over three dimensional nonlinear stretched surface with passive control of mass flux and chemically responsive species," Multidiscipline Modeling in Materials and Structures, vol. 16, no. 5, 2020.

[27] M. Sohail and S. Tariq, "Dynamical and optimal procedure to analyze the attributes of yield exhibiting material with double diffusion theories," Multidiscipline Modeling in Materials and Structures, vol. 16, no. 3, 2019.

[28] R. R. Rangi and N. Ahmad, "Boundary layer flow past a stretching cylinder and heat transfer with variable thermal conductivity," Applied Mathematics, vol. 3, no. 3, 2012. 